\title{
Imposed strain localization in the lower crust on seismic timescales
}

\author{
Susan Ellis ${ }^{1}$ and Bernhard Stöckhert ${ }^{2}$ \\ ${ }^{1}$ Geological and Nuclear Sciences, 69 Gracefield Rd, Lower Hutt, New Zealand \\ ${ }^{2}$ Institute of Geology, Mineralogy, and Geophysics, Ruhr University, Bochum, Germany
}

(Received April 30, 2004; Revised November 19, 2004; Accepted December 3, 2004)

\begin{abstract}
We show using numerical model experiments that upper crustal faults can impose ductile localization in the mid and lower crust over the seismic cycle, with strain-rates and integrated creep strain enhanced by a factor of 10 , or a factor of 100 if lower crust is also thermally weakened. Imposed ductile localization is caused by the transfer in stress from the lower tip of the frictional fault to the mid-crust. Within the weak ductile mid-lower crust, this stress transfer also promotes significantly enhanced creep rates in a lobe that extends down-dip from the lower end of the fault. Comparison of model results with the Alpine Fault of New Zealand, shows how the interaction of faulting with other localization mechanisms can account for key aspects of the geodetic strain accumulating across the Alpine Fault. Localization of ductile strain in the lower crust imposed by faulting in the upper crust could explain the extension of major faults into the lower crust observed in seismic imaging.
\end{abstract}

Key words: Strain, localization, model, crust, rheology, fault, Alpine Fault, stress.

\section{Introduction}

While deformation in the upper crust is obviously focused along brittle faults, the degree and principal causes of localization in lower crust are still debated. Strain analysis in mylonites exhumed from mid and lower crustal depths indicates significant localization (e.g., Norris and Cooper, 2003) and major faults such as the Alpine Fault of New Zealand can be traced to the lower crust using geophysical observations (Davey et al., 1995; Stern et al., 2001). However, in general it has not been possible to establish how much of the plate boundary motion is accommodated along ductile shear zones in the lower crust. A related question is whether ductile shear zones are "active" in the sense that they load stress onto overlying faults during the interseismic period, or whether these shear zones passively relieve stresses transferred from faults.

Montesi and Zuber (2002) consider which processes can lead to localization in ductile lower crust, and categorise them into those inherited from previous deformation phases, those that are imposed (forced) by external processes such as erosion and faulting, and dynamic localization resulting from the inherent localization properties of the material under applied stress (e.g., see summary in Regenauer-Lieb and Yuen, 2003). Here, we suggest that imposed localization can in certain cases account for a large proportion of the strain observed in exhumed mylonite zones. In particular, we explore the transfer of stress from a weak frictional fault to ductile flow using numerical model experiments. These experiments demonstrate that stress perturbations associated with the lower termination of fault slip can cause significant localization in ductile mid-

Copy right(c) The Society of Geomagnetism and Earth, Planetary and Space Sciences (SGEPSS); The Seismological Society of Japan; The Volcanological Society of Japan; The Geodetic Society of Japan; The Japanese Society for Planetary Sciences; TERRAPUB lower crust.

\section{Numerical Model Experiments}

2.1 Model 1: Lower crust with uniform geothermal gradient

The numerical finite element analysis is conducted using the Abaqus software (Hibbitt et al., 2001). We consider an initially homogeneous crustal layer, $30 \mathrm{~km}$ thick, with a frictional weakness (fault) dipping at $45^{\circ}$ (Fig. 1(a)). The geometry roughly coincides with the present-day geometry of the Alpine Fault of New Zealand (Norris and Cooper, 2003), although we only model the normal component of motion along it. The fault is represented by a contact surface with a specified angle of friction, weaker than surrounding crust, which deforms by a combination of linear elasticity, Coulomb frictional plasticity, and thermallyactivated power-law creep. The transition from frictional to ductile behaviour is determined naturally by the model, according to the applied geothermal gradient, ambient pressure and strain-rates, and assumed creep parameter values for wet quartz (Paterson and Luan, 1990). For simplicity, we assume hydrostatic fluid pressure throughout the model run, although we acknowledge that fluid pressure variations may play an important role in the seismic cycle (e.g., Miller et al., 1999; Hobbs et al., 2004).

The maximum Coulomb shear stress $\tau_{y}$ along any optimally oriented plane is computed for an internal angle of friction $\phi=30^{\circ}$ (i.e. approximately Byerlee's law conditions) and a cohesion $C=1 \mathrm{MPa}$. The effective mean stress $p^{\prime}=p-p_{f}$, where $p$ is total (mean) stress and $p_{f}$ is the fluid pressure, is used in the equation:

$$
\tau_{y}=p^{\prime} \sin (\phi)+C \cos (\phi)
$$

where maximum shear stress $\tau_{y}$ is half of the maximum differential stress, $\tau_{y}=(1 / 2)\left(\sigma_{1}-\sigma_{3}\right)$ and the indices 1 and 3 
(a) Initial and boundary conditions

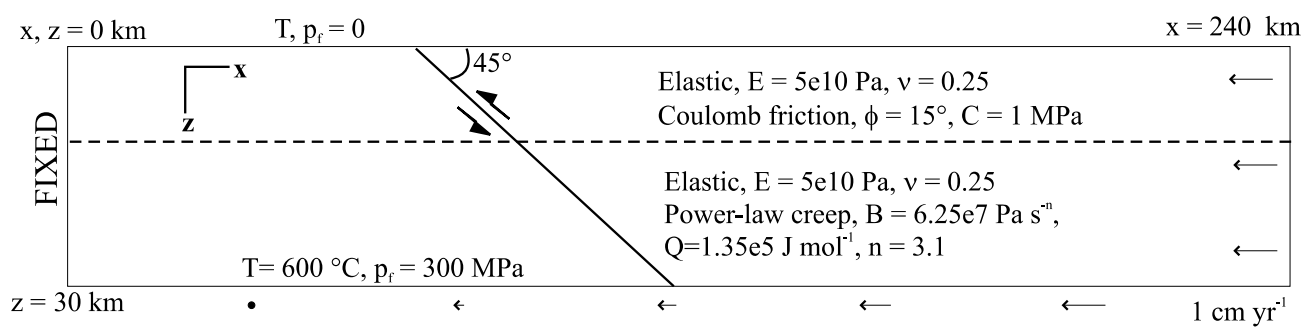

(b) Differential stress after steady-state phase

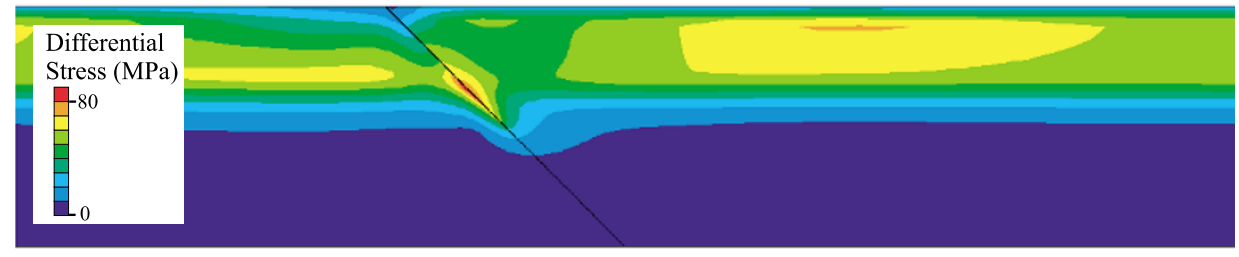

(c) Log (strain-rate invariant) immediately after faulting, 1 seismic cycle

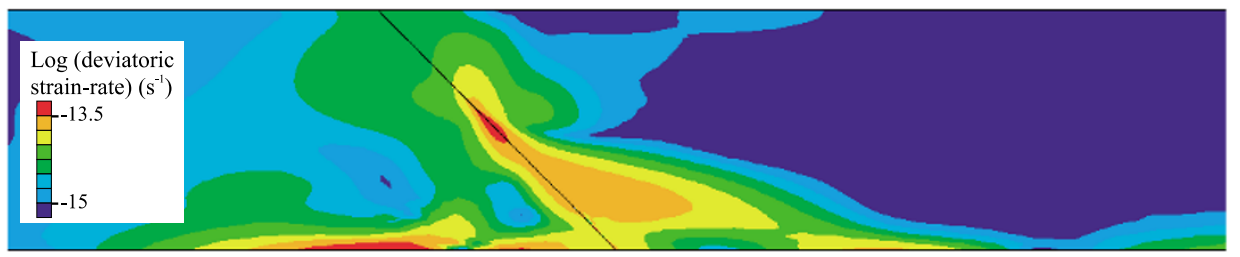

(d) Accumulated creep strain after 8 seismic cycles

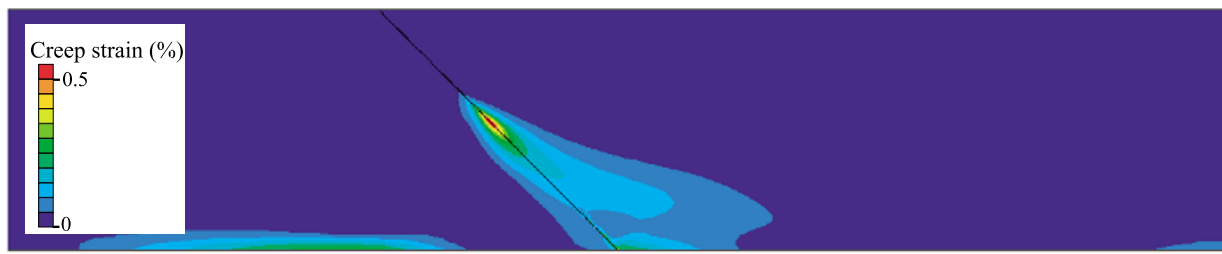

(e) Slip along fault (fault step)

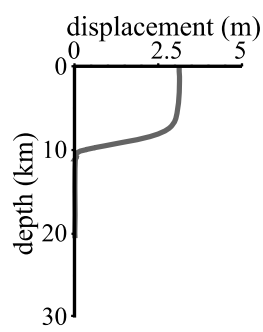

(f) Change in differential stress (fault step)

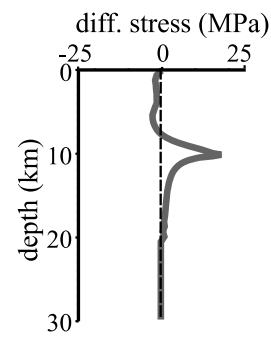

(g) Change in differential stress (interseismic step)

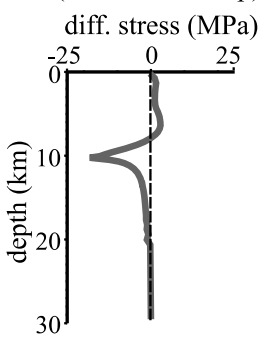

Fig. 1. (a) Two-dimensional numerical model setup for model 1. Details of rheology are given in the text. Dashed line represents brittle-ductile transition. A uniform horizontal shortening rate of $1 \mathrm{~cm} \mathrm{yr}^{-1}$ is applied to the right-hand boundary of the model. Deformation of underlying layers is represented by distributed shortening on the lower boundary. Pore pressure and temperature increase linearly with depth. (b) Color contours of differential stress for the whole model domain at the end of the setup phase (300 m convergence). (c) Log contour of second invariant of deviatoric strain-rate immediately after the fault step, where the friction coefficient along the fault was dropped to 0.1.(d) Integrated creep strain for 8 complete seismic cycles corresponding to 4000 years. (e) Slip along fault plane during the fault step. (f) Change in differential stress along the fault plane during the fault step. (g) Change in differential stress along the fault plane during the interseismic step.

refer to maximum and minimum principal stresses, respectively (e.g., Mandl, 1988). No strain-softening as a result of fault damage is applied in the model rocks surrounding the fault tip. Power-law ductile creep follows the constitutive equation:

$$
\tau_{v}=B \dot{\varepsilon}^{1 / n} \exp (Q / n R T)
$$

where $\tau_{v}$ and $\dot{\varepsilon}$ are the second invariants of the deviatoric stress and strain-rate tensors, respectively, $Q$ is activation energy, $n$ is the power-law exponent, $R$ the universal gas constant, and $T$ is temperature $(\mathrm{K})$. (Individual deviatoric strain-rate tensor components are related to equivalent deviatoric stress tensor components using the effective viscosity derived from (2)). $B$ is related to the pre-exponential constant, $A$, by:

$$
B=\left(3^{-(n+1) / 2 n} 2^{1-n / n}\right) A^{\frac{-1}{n}}
$$


The geometric factor in brackets is necessary for conversion from uniaxial creep laboratory data. $A$ is determined (as are $Q$ and $n$ ) from laboratory creep experiments on wet synthetic quartzite (Paterson and Luan, 1990).

In the first experiment (Fig. 1), we impose a uniform frictional coefficient $\mu=0.1$ along the fault from the surface to the base of the model crust. A coefficient of 0.1 represents a weak fault that may have undergone strain weakening and be subject to fluid overpressure, and is consistent with inferences of low fault strength from heat-flow observations along major faults (e.g., Lachenbruch and Sass, 1980). A start-up phase during which compression is applied at the right hand boundary at a rate of $1 \mathrm{~cm} / \mathrm{yr}$ (time interval 30,000 years i.e. $300 \mathrm{~m}$ of convergence), is used to simulate the long-term build up of differential stress, which gradually accumulates in the strong, frictional upper crustal layer (Fig. 1(b)). During the start-up phase, we do not prescribe slip along the fault. Instead, the contact algorithm in Abaqus determines slip as a function of depth and time. The result is that the fault slips steadily along its upper portion (the top ca. $10 \mathrm{~km}$ ) once frictional yield is exceeded. Frictional slip tapers off in the mid-crust because the ductile mid-lower crust becomes weaker than the frictional surface with increasing pressure and temperature. As a result, at mid-crustal depths and below, ductile flow takes over from the frictional motion along the contact surface, as described in similar models by Cattin and Avouac (2000) and Chéry et al. (2001).

Differential stresses $>70 \mathrm{MPa}$ build up around the lower termination of the actively slipping fault (ca. 8-11 km depth, Fig. 1(b)). This stress build-up results from the termination of slip over this depth interval, in the region where frictional faulting gives way to thermally activated ductile creep. The slipping fault loads the surrounding mid-crust elastically, by an amount that depends on the elastic strength of the medium and the depth range over which slip tapers, $\delta$ (ca. $3 \mathrm{~km}$ ). The stress build-up is limited by the ability of the mid-crust to relax differential stress by ductile flow, so that a steady-state is reached, where additional increments in elastic strain are relieved by creeping at the same rate:

$$
\frac{\dot{\varepsilon}_{\text {elastic }}}{\dot{\varepsilon}_{\text {viscous }}}=1 \approx \frac{V / \delta}{A \tau_{s s}^{n} \exp (-Q / R T)}
$$

so that

$$
\tau_{s s}=\left(\frac{V}{A \delta}\right)^{\frac{1}{n}} \exp \left(\frac{Q}{n R T}\right)
$$

where $V$ is slip velocity, $\dot{\varepsilon}$ is strain-rate, and the other variables are as defined above. For the parameter values used here, $\tau_{s s}$ is about $80 \mathrm{MPa}$ for a steadily creeping fault with the frictional-ductile transition along the fault occurring at a temperature of about $260^{\circ} \mathrm{C}$, verifying the numerical model result (Fig. 1(b)).

After the start-up phase, the fault is locked for a specified period of 500 years, simulating the interseismic part of the seismic cycle, and then fault friction is reduced back down to its initial value for a short period (1 day), simulating the static response to the faulting step of the seismic cycle. No dynamic or rate-state effects are modelled. Results for strain-rate at the end of 1 seismic cycle (i.e. just after the fault step), and integrated ductile creep after 8 seismic cycles, are shown in Fig. 1(c)-(d).

The elevated stresses at the lower termination of the fault, initially due to steady fault slip during the setup phase (Fig. 1(b)) and then enhanced by sudden slip every 500 years, cause localization in ductile straining in the mid and lower crust beneath the fault (e.g., Fig. 1(c)). Strain-rates attain their maximum just after the fault step is completed, when mid-crustal differential stresses along the fault plane are highest. Strain is enhanced in a lobe dipping beneath the fault and down to the base of the crust. The elevated strain-rates are directly caused by termination of fault slip, and there is no component of dynamic ductile localization (as defined by Montesi and Zuber, 2002) since the model contains no dynamic localization mechanism. Instead, focused ductile shearing occurs due to the imposed and localized stress transfer from the fault. After 8 seismic cycles, the accumulated creep strain (Fig. 1(d)) beneath the fault is ca. $10 \times$ background rates.

In cases where fault slip tapers more suddenly than that shown here, for example due to asperities or changes in fault geometry, even larger stresses may build up at the fault termination. Ellis and Stöckhert (2004) illustrate this behaviour for a steep thrust fault terminating over $1 \mathrm{~km}$ depth, and compare it to microstructural observations from the Sesia Zone, European Alps, suggesting that in some cases stresses of over $300 \mathrm{MPa}$ may be induced by earthquakes, causing deformation of the ductile crust at strain rates more than two orders of magnitude above background rates. Even for the comparatively "smooth" fault case examined here, the seismically induced perturbation of the stress field beneath the fault tip causes significant localized deformation along the extension of the fault in the ductile lower crust.

Total slip of about $4 \mathrm{~m}$ occurs along the fault surface during each fault step (Fig. 1(e)). The change in differential stress along the fault during the seismic cycle is shown in Figs. 1(f) and (g). Stress changes result from elastic loading and unloading of the crust near the fault plane, and their magnitude depends on the elastic strength, and the interplay between elastic and viscous rheologies in the mid-crust. The stress changes for seismic and interseismic steps are almost exact mirror images of each other, indicating that the model has attained a kind of "steady state" where short-term stress changes during the seismic cycle oscillate around the stress field shown in Fig. 1(b). During the faulting step (Fig. 1(f)), a stress drop is observed over most of the upper crustal fault plane, but a stress increase of about 20 MPa occurs at the lower termination of the fault. This stress is entirely relieved by ductile creeping during the subsequent interseismic step (Fig. 1(g)), along with a small stress increase over the upper $8 \mathrm{~km}$ of the fault surface. The stress drops during faulting in the top $8 \mathrm{~km}$ of the model are consistent with small stress drops inferred from seismic observations (Bouchon, 1997; McGarr and Fletcher, 2002) but the stress increases between $8-12 \mathrm{~km}$ depth suggest that the stress behaviour may be quite different in the (probably aseismic) semi-brittle mid-crust.

2.2 Model 2: Thermally weakened zone in lower crust

The loading of a fault by ductile shearing can be shown to be even more significant for a model in which the lower 
(a) Perturbation in temperature field

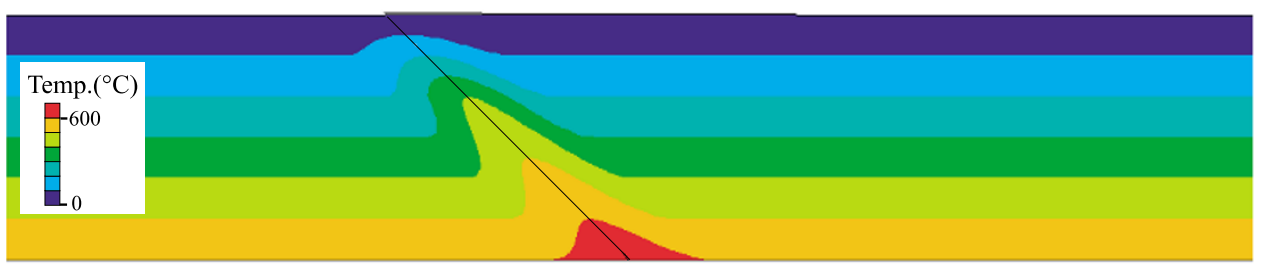

(b) Differential stress after setup phase

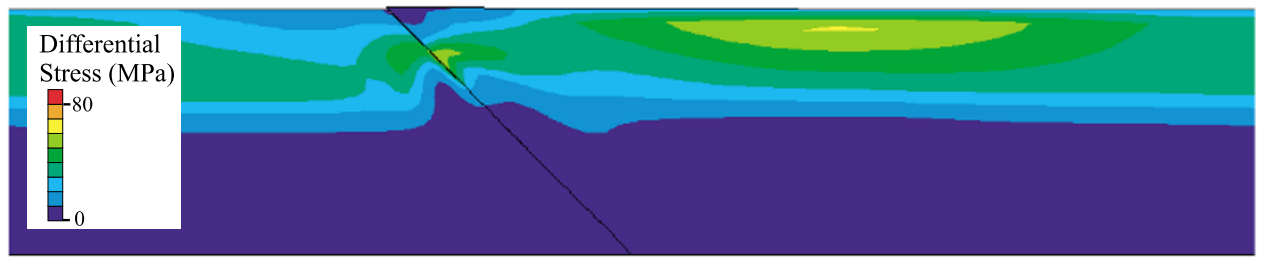

(c) Log (strain-rate invariant) immediately after faulting, 1 seismic cycle

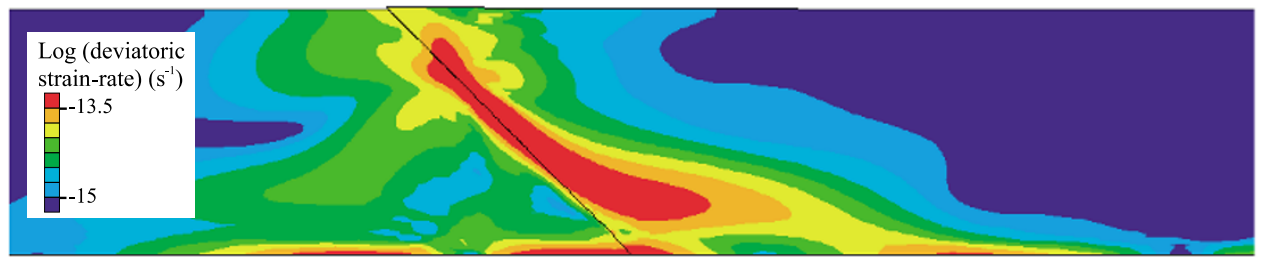

(d) Accumulated creep strain after 8 seismic cycles

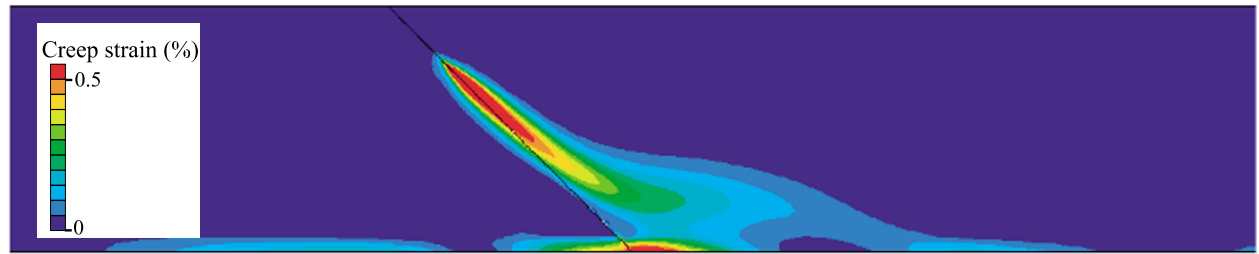

(e) Slip along fault (fault step)

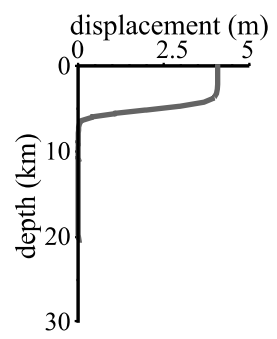

(f) Change in differential stress (fault step)

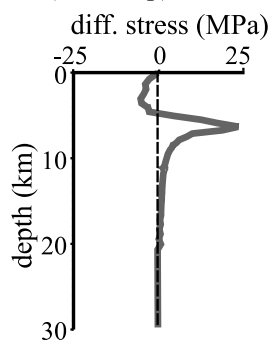

(g) Change in differential stress (interseismic step)

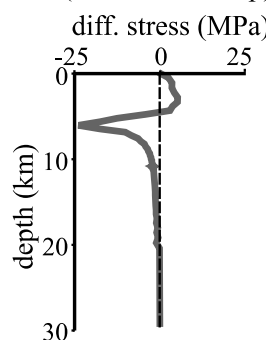

Fig. 2. (a) Contours of temperature for model 2, which has the same setup as model 1 apart from the imposed perturbation in the temperature field. (b) Color contours of differential stress for the whole model domain at the end of the setup phase (300 m convergence). (c) Log contour of second invariant of deviatoric strain-rate immediately after the fault step. (d) Integrated creep strain for 8 complete seismic cycles corresponding to 4000 years. (e) Slip along the fault plane during the fault step. (f) Change in differential stress along the fault plane during the fault step. (g) Change in differential stress along the fault plane during the interseismic step.

crust has experienced some form of thermal weakening. Thermal weakening can occur due to localization via shear heating during repeated deformation along a high-strength fault or shear zone (a form of dynamic localization; e.g., Thatcher and England, 1998). Thermal weakening can also result from focused erosion and exhumation (a form of imposed localization), which deflect isotherms upwards along or near the shear zone (Koons et al., 2003; Beaumont et al., 1992; Batt and Braun, 1999). To investigate the effects of weakened lower crust, we prescribe a thermal perturbation in a model that is otherwise identical to the one discussed above (Fig. 2(a)). The thermal perturbation causes an increased geothermal gradient directly around the fault and its extension into the lower crust, similar to that predicted due to erosional exhumation in small collisional orogens such as the New Zealand Southern Alps (Koons et al., 2003; Beaumont et al., 1992; Batt and Braun, 1999).

The major effect of the thermal perturbation cf. model 1, is to reduce the depth and magnitude of differential stress that builds up around the fault plane (Fig. 2(b)). This is 
(a)

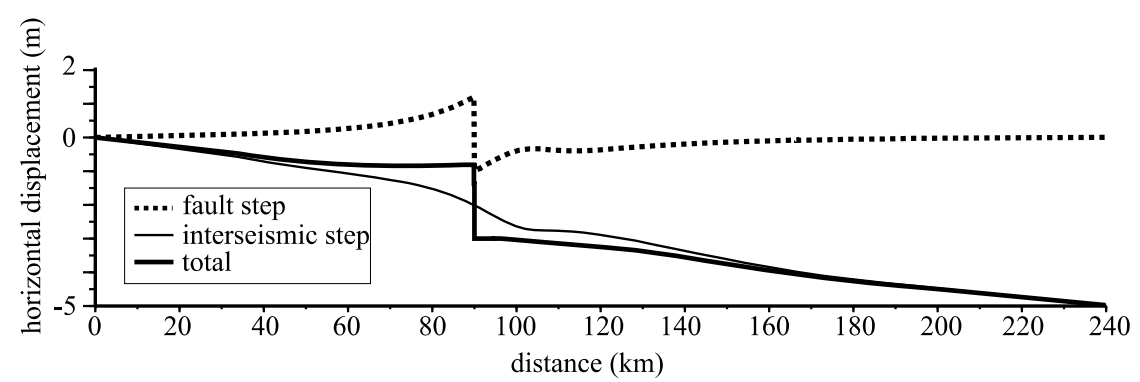

(b)

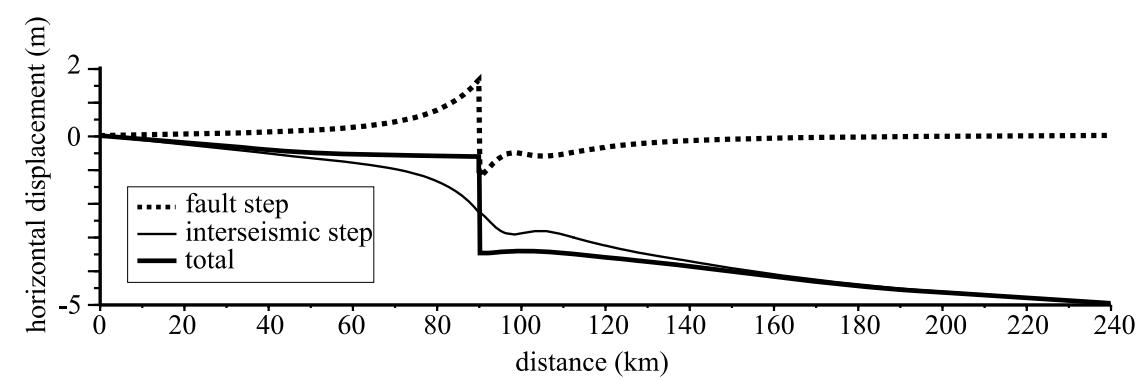

Fig. 3. Plot of total horizontal displacement during one seismic cycle, and displacement of interseismic/seismic component parts, for (a) Model 1 (b) Model 2. Fault intersects surface at $x=90 \mathrm{~km}$.

because slip decreases at shallower depths compared to the first model, owing to the greater geothermal gradient (Fig. 2(e)). Despite the lower stresses, strain rates just after the fault step of a seismic cycle are much higher than for Fig. 1 (Fig. 2(c)). The higher strain rates result from higher temperatures in this region, with strain rates exceeding $10^{-12} \mathrm{~s}^{-1}$ immediately after faulting. Integrated over several seismic cycles, this results in a much more focused lobe of creep strain beneath the fault (Fig. 2(d)), with creep strain ca. $100 \times$ background levels.

Plots of stress change in the coseismic and interseismic steps (Figs. 2(f) and (g)) show that the change in stress at the depth of slip termination is greater than for the model with no thermal perturbation (Fig. 1(f) and (g)). The fact that the model 2 background stress level (Fig. 2(b)) is lower than for model 1, whereas the stress change at the fault tip is higher, may seem counter-intuitive. The explanation is that the thermal perturbation has caused localization of flow in the lower crust, which loads the fault during the interseismic period. This enhances the stress transfer between lower and upper crust, despite the fact that the background stress is lower due to enhanced creep. The stress changes at the tip of the fault during the seismic cycle are a greater proportion of total stress, but these stress changes are relieved at a faster rate, so that the "steady state" background stress is lower.

\subsection{Is the fault loaded from below?}

We return to the question asked in the introduction: is motion along the ductile shear zone beneath the fault contributing to "stress loading" of the fault during the interseismic period? If no fault were present, we have calculated that for our model dimensions and interseismic velocity the upper crust would be loading elastically at uniform rate of $1 \mathrm{MPa}$ every 500 years. In model 1 , the upper part of the fault plane loads by about $1.8 \mathrm{MPa}$ over 500 years during the interseismic step (Fig. 1(g)). This indicates that a small enhancement in stress loading along the fault is provided by ductile shearing. Although there is no dynamic weakening of lower crust, we suspect that this effect is caused by strainrate weakening in the high-strain zone beneath the fault. In model 2, the fault in the upper crust loads by ca. $4.8 \mathrm{MPa}$ over 500 years (Fig. 2(g)), indicating that in this case, weakened ductile crust beneath the fault is loading stress along the fault tip at over $4 \times$ the background rate.

\subsection{Horizontal surface displacement over the seismic cycle}

Plots of interseismic, seismic, and total horizontal displacement at the surface over the 500 year seismic cycle (Fig. 3) demonstrate that total cumulative horizontal strain is focused around the fault for both model 1 and model 2 , with a steeper gradient in horizontal displacement near the fault predicted for the case with thermal weakening (model 2). Distributed horizontal motion occurs during the interseismic period over two superimposed wavelengths: (1) $>200 \mathrm{~km}$, indicating that some of the strain is taken up by distributed elastic strain throughout the model; and (2) a shorter wavelength $<50 \mathrm{~km}$, due to the elevated creeping occurring beneath the fault. The dimensions of the shorter wavelength are related to the dip of the shear zone, and the depth at which shearing initiates, i.e. the depth of the transition from "locked" behaviour along the fault and surrounding crust, to localized ductile creeping. This depth is about $10 \mathrm{~km}$ in Model 1 and $6 \mathrm{~km}$ in Model 2.

\section{Implications for the Seismic Cycle of the Alpine Fault, New Zealand}

The New Zealand Southern Alps formed in response to oblique collision between the Pacific and Australian 
plates over the past 5-7 Ma (Walcott, 1998 and references therein). The Alpine Fault marks the western boundary of the Southern Alps, and presently accommodates about $70 \%$ of relative plate motion in the central South Island (Norris and Cooper, 2001; Beavan et al., 1999). Seismic velocity anomalies and wide angle reflections along the down-dip trend of the surface fault have been imaged in a geophysical transect across the central Southern Alps (Stern et al., 2001), suggesting that the Alpine Fault is a major crustal structure that continues as a localized shear zone at depths of more than $30 \mathrm{~km}$. Studies of high strain mylonites exhumed structurally above the Alpine Fault also indicate that strain is localized at depths of $20 \mathrm{~km}$ or more along a narrow mylonitic shear zone (Norris and Cooper, 2003).

A principal control on long-term Alpine Fault dynamics is the rapid uplift and exhumation of hot material along the fault ramp (Koons et al., 2003; Batt and Braun, 1999; Little et al., 2002; Gerbault et al., 2003). The Alpine Fault region can therefore be considered to be thermally weakened compared to surrounding material, as in Model 2. It should be noted that the geometry and conditions in Model 2 are highly stylized compared to the Alpine Fault. In particular, the model has no strike-slip component of motion, or variations in topography, crustal thickness, and rheology apart from the thermal perturbation; and the presence of other (secondary) weak faults within the brittle crust is not considered.

Although the geometry of Model 2 is highly simplified with respect to the real Alpine Fault, we suggest that several of the observations discussed in relation to Model 2 (Fig. 2) can be used to provide insight into the Alpine Fault seismic cycle:

1. Interseismic surface displacement normal to the Alpine Fault measured by GPS geodesy (Beavan et al., 1999; Beavan et al., 2004) shows a superposition of a shortwavelength signature of ca. $20 \mathrm{~km}$ whose amplitude is about half of the available normal convergent displacement across the plate boundary, and a longer wavelength signal (ca. $100 \mathrm{~km}$ ) which has been interpreted as an elastic response to deformation of mantle lithosphere beneath the collision zone. The short-wavelength signal is similar to that shown in Model 2 (Fig. 3(b)). Beavan et al. (1999, 2004) have inverted the surface displacement and solved for slipping zones beneath the (currently locked) Alpine Fault. Their most recent best-fit model predicts slip along the down-dip extension of the Alpine Fault, with the upper locked part of the fault ending at a depth of $7 \mathrm{~km}$ (Beavan et al., 2004). This is similar to the depth of transition from "locked" to "creeping" behaviour seen in Model 2 (Fig. 2(c) and (d)). Given the similarity, we interpret the slipping patch described in Beavan et al. (2004) as a zone of enhanced ductile creep, caused by a combination of thermal weakening and the interseismic response to seismic stress loading from the fault itself.

2 . In the numerical models, the lower boundary condition is prescribed so that the incoming velocity gradually reduces across the width of the model $(240 \mathrm{~km})$. This produces a broad-wavelength surface displacement that is equal to the model width (Fig. 3). In the case of the New Zealand Southern Alps, a broad wavelength signal is ob- served, but its wavelength is only ca. $100 \mathrm{~km}$. This suggests that mantle lithosphere beneath the Southern Alps must be deforming over a wavelength less than $100 \mathrm{~km}$.

3. Geological estimates suggest that between 60 and $75 \%$ of total plate motion is ultimately taken up by rupture along the Alpine Fault (Norris and Cooper, 2001). This is compatible with predictions from Model 2 (Fig. 3(b)) in which the normal component of interseismic deformation occurs over a longer wavelength compared that of the integrated seismic cycle.

4. Fig. 2(d) shows how ductile creep can become focused beneath a fault with repeated seismic cycles, especially if accompanied by thermal weakening. The analogy with Model 2 may help explain the presence of a localized ductile shear zone extending into the lower crust beneath the Alpine Fault.

5. If interseismic creep below the Alpine Fault is enhanced by the stress transfer during faulting such as in Models 1 and 2, then it can be shown that the creep rate and accompanying degree of localization will gradually decay with time after faulting. For example, analysis of the interseismic surface velocities in Model 2 indicates that early in the interseismic period, more than $80 \%$ of the available convergent velocity is taken up within $30 \mathrm{~km}$ of the fault zone, whereas by the end of the interseismic period, only $40 \%$ is absorbed near the fault and the rest is distributed over a wavelength that depends on the behaviour of underlying lithosphere. The slow but measurable drift in the degree to which interseismic surface velocities are focused around the Alpine Fault as the seismic cycle "matures" may provide an additional constraint for hazard estimation.

Acknowledgments. This work was supported by the New Zealand Foundation for Research, Science and Technology and by the German Science Foundation within the scope of Collaborative Research Center 526. We thank Yoshihisa Iio for a thoughtful and constructive review. Some of the ideas behind this paper resulted from helpful discussions with Jean Chéry, Joan Gomberg, Paul Bodin, Jim Dieterich, Georg Dresen, Tim Little, and the Slip and Flow symposium participants. Comments from John Beavan, Laura Wallace, and Martin Reyners helped improve the manuscript.

\section{References}

Batt, G. and J. Braun, The tectonic evolution of the Southern Alps, New Zealand; insights from fully thermally coupled dynamical modelling, Geophys. J. Int., 136, 403-420, 1999.

Beaumont, C., P. Fullsack, and J. Hamilton, Erosional control of active compressional orogens, in Thrust Tectonics, edited by K. R. McClay, pp. 1-18, Chapman and Hall, New York, 1992.

Beavan, J., and 10 others, Crustal deformation during 1994-1998 due to oblique continental collision in the central Southern Alps, New Zealand, and implications for seismic potential of the Alpine Fault, J. Geophys. Res., 104, 25233-25255, 1999.

Beavan, J., and 6 others, A vertical deformation profile across the Southern Alps, New Zealand, from 3.5 years of continuous GPS data, Cahiers de Centre Européen de Géodynamique et Séismologie, Proceedings of the Workshop: The state of GPS vertical positioning precision: Separation of earth processes by space geodesy, edited by T. van Dam, 24, 2004.

Bouchon, M., The state of stress on some faults of the San Andreas as inferred from near-field strong motion data, J. Geophys. Res., 102, 1173111744, 1997.

Cattin, R. and J. Avouac, Modeling mountain building and the seismic cycle in the Himalaya of Nepal, J. Geophys. Res., 105, 13389-13407, 2000

Chéry, J., M. Zoback, and R. Hassani, An integrated mechanical model of 
the San Andreas fault in Central and Northern California, J. Geophys. Res., 106, 22051-22066, 2001.

Davey, F., T. Henyey, S. Kleffmann, A. Melhuish, D. Okaya, T. Stern, and D. Woodward, Crustal reflections from the Alpine Fault zone, South Island, New Zealand, New Zealand J. Geol. Geophys., 38, 601-604, 1995.

Ellis, S. and B. Stöckhert, Elevated stresses and creep rates beneath the brittle-ductile transition caused by faulting in the upper crust, J. Geophys. Res., 109, B05407, doi:10.1029/2003JB002744, 2004.

Gerbault, M., S. Henrys, and F. Davey, Numerical models of lithospheric deformation forming the Southern Alps of New Zealand, J. Geophys. Res., 108(B7), 2341, doi:10.1029/2001JB001716, 2003.

Hibbitt, Karlsson, and Sorensen, Abaqus/Standard User's Manual, vol. 1 and 2, version 6.2, Hibbitt, Karlsson, and Sorensen Inc., Pawtucket, 2001.

Hobbs, B., A. Ord, and K. Regenauer-Lieb, Fluid reservoirs in the crust, seismic activity and mechanical coupling between the upper and lower crust, abstract, 2nd Intl Symposium on slip and flow processes in and below the seismogenic region, Tokyo, Mar 10-14, 2004.

Koons, P., R. Norris, D. Craw, and A. Cooper, Influence of exhumation on the structural evolution of transpressional plate boundaries: an example from the Southern Alps, New Zealand, Geology, 31, 3-6, 2003.

Lachenbruch, A. and J. Sass, Heat flow and energetics of the San Andreas Fault zone, Journal of Geophysical Research, 85, 6185-6222, 1980.

Little, T., R. Holcombe, and B. Ilg, Kinematics of oblique continental collision inferred from ductile microstructures and strain in mid-crustal Alpine schist, central South Island, New Zealand, Journal of Structural Geology, 24, 219-239, 2002.

McGarr, A. and J. Fletcher, Mapping apparent stress and energy radiation over fault zones of major earthquakes, Bull. Seis. Soc. Am., 92, 16331646, 2002.
Miller, S., Y. Ben-Zion, and J.-P. Burg, A three-dimensional fluidcontrolled earthquake model: Behavior and implications, J. Geophys. Res., 104, 10621-10638, 1999.

Montesi, L. and M. Zuber, A unified description of localization for application to large-scale tectonics, J. Geophys. Res., 107(B3), 10.1029/2001JB000465, 2002.

Norris, R. and A. Cooper, Late Quaternary slip rates and slip partitioning on the Alpine Fault, New Zealand, J. Struc. Geol., 23, 507-520, 2001.

Norris, R. and A. Cooper, Very high strain-rates recorded in mylonites along the Alpine Fault, New Zealand: Implications for the deep structure of plate boundary faults, J. Struc. Geol., 25, 2141-2157, 2003.

Paterson, M. and F. Luan, Quartzite rheology under geological conditions, in Deformation Mechanisms, Rheology and Tectonics, edited by R. J. Knipe and E. H. Rutter, 54, Geol. Soc. Lond. Spec. Publ., pp. 299-307, 1990.

Regenauer-Lieb, K. and D. Yuen, Modeling shear zones in geological and planetary sciences: Solid- and fluid-thermal-mechanical approaches, Earth Sci. Rev., 63, 295-349, 2003.

Starr, A., Slip in a crystal and rupture in a solid due to shear, Proc. Cambridge Philos. Soc., 24, 489-500, 1928.

Stern, T., S. Kleffmann, D. Okaya, M. Scherwath, and S. Bannister, Low seismic-wave speeds and enhanced fluid pressure beneath the Southern Alps of New Zealand, Geology, 29, 679-692, 2001.

Thatcher, W. and P. England, Ductile shear zones beneath strike-slip faults: Implications for the thermomechanics of the San Andreas fault zone, $J$. Geophys. Res., 103, 891-905, 1998.

Walcott, R., Modes of oblique compression: Late Cenozoic tectonics of the South Island of New Zealand, Rev. Geophys., 36, 1-26, 1998.

S. Ellis (e-mail: S.Ellis@gns.cri.nz) and B. Stöckhert 